\title{
THE PHENOMENA OF TRUSTING AND
}

\section{RELATIONAL ONTOLOGIES}

My aim in this essay is to show connections between the phenomena of trusting and some types of ontology, specifically of relational ontologies. The commerce between trustings' phenomena and ontologies goes both ways. Insofar as the phenomena fit the ontologies, the phenomena serve to confirm the ontologies. Insofar as the ontologies suggest what to look for as phenomena, and how to interpret phenomena, the ontologies contribute to the understanding of trust, within the hermeneutic circle. With baseball pitches and the umpire's call, an accurately called strike depends not only on the trajectory of the ball but also on the double frame of the batter's stance and the plate's plane and outline--so baseball cognoscenti tell me; analogously, trust gets recognized accurately--a prelude to its being evaluated--not only on the basis of the intentional act, but also on the basis of the dimensions according to which it is charted. For trust, I use the term "dimensions" to suggest that greater or less trust is not to be charted along just one axis; the particular shape of a person's trusting requires more than one dimension.

Among relational ontologies I will take a look at some feminist thought, the thought of Martin Buber, and the thought of Gabriel Marcel.

I offer only a sketch of the phenomena of trust. While I myself recognize four dimensions of trusting (reliance-trusting; 1-thou trusting, security-trusting, and openness-trusting), in this essay I will treat only two of the four: reliance trust and I-Thou trusting.

\section{RELIANCE TRUST}

To rely is first of all to expect: it is to count on something happening, and to take appropriate steps to deal with that future outcome. To trust is, in most usages, to expect what is also desired, or what is a good for me or for another. But to rely is not merely to have an expectation. It is also to act on an expectation, or at least to 
be disposed to act on an expectation. 1

Because I think it more conceptually and experientially fruitful, I choose to begin analyzing trust in terms of acting on expectations, rather than to begin by taking trusting as a propositional attitude, or as a kind of believing, or as acting as if, especially acting as if I believed.2

Initially I set aside reliance on things, and focus on relying on persons. I also initially set aside two contexts that often figure prominently in reflection on trust, the involuntary reliance of the infant and the highly specific and usually sanctioned relationships of promising between adults that is known as a contract. I take as my paradigm of reliance-trusting a dealing between adults that is neither contractual nor involuntary.

With persons, a key feature of trusting is that of appealing to the good will of another. There is a difference between relying on natural processes and relying on persons. I can rely on salt to season and not to poison, but this is different from relying on my cook to season and not to poison. With nature $\mathrm{I}$ am expecting and counting on processes to continue as they have been. With persons I am sometimes counting on someone's good will, or at least lack of ill will,

1Expectation, and acting on an expectation, is central to the way trust is defined by Annette Baier, "Trust and Anti-Trust" Ethics 96 (January 1986): 231-260, and by Bernard Barber, The Logic and Limits of Trust (New Brunswick: Rutgers, 1983). It is also central to understanding religious faith as trust, as Jaroslav Pelikan surveys the matter in "Faith," The Encyclopedia of Religion (New York: Macmillan, and London: Collier Macmillan, 1987), 5:252.

2Trust understood as acting as if is the analysis favored by Richard Swinburne, Faith and Reason (Oxford: Clarendon Press, 1981). See also John King-Farlow and William Christensen on faith and hypotheses in "Faith-and Faith in Hypotheses," Religious Studies 7 (June 1971): 113-124. 
towards me. ${ }^{3}$

But trusting is not merely a matter of expecting and counting on what is desired from someone else, and acting with hope in light of that expectation. 4 Something else is needed: letting help. To trust a person is to desire and expect and act so as to enable another freely to help me and thus so as to increase a kind of likelihood that the other will help me.5

To act trustingly is to act or refrain from acting so as to let someone help and thereby to increase the likelihood that the other will help obtain what I want or need. How do I let help and thereby increase this likelihood? How do I act so as to have another's helping

3Annette Baier contrasts trusting others and merely relying on them. Trusting involves another's good will or at least minimal ill will, whereas merely relying counts on only "their dependable habits or dependably exhibited fear, anger, or other motives compatible with ill will toward one, or on motives not directed on one at all. ... W We all depend on one another's psychology in countless ways, but this is not yet to trust them." Trusting can be betrayed; other reliances are disappointed. Baier, "Trust and Antitrust," Ethics 96 (January 1986): 234-235.

4 On hope as a conjoining of desire and estimated possibility see my $A$ Philosophy of Human Hope (Dordrecht: Martinus Nijhoff, 1987), 29-32.

5Suspicion is defined as parallel to reliance-trust. To be suspicious is to fear harm, that is, to think that harm is possible, and to desire that it not occur (or that it not have occurred)--harm due to ill will, indifference, or incompetence--and therefore is to be disposed to take preventive or protective or risk-minimizing measures, such as by removing a good from another's range of acting. To act with suspicion or to act warily is to resist vulnerability to someone's ill will, negligence, or incompetence. This primary sense of suspicion is based on a person's reliability; a thing's reliability is derivative: to be suspicious of something is to resist vulnerability to something's lack of reliable functioning. 
me be an effect of my acting? 6 I can affect this likelihood by entrusting or by not preventing or by not discouraging another's initiative. I afford an opportunity to help. I allow a good to be within the causal range of another's action. I commit or entrust; or at least I do not withdraw.

Furthermore, trust is often specific and delimited in the matter or good that is entrusted and in what outcomes are expected and desired. Such specificities can have a range, established by discretion extended or discretion withheld. A parent relies on a baby sitter to perform some specific services for his or her children, explicitly excluding others; yet even after instructions, much is left to the sitter's discretion.

So far, analyzing trust as reliance takes trusting to involve a set of four factors: there is the I who entrust, the other who is relied upon, the matter or good entrusted, and the outcome expected and desired, with varying degrees of discretion.7

There is a fifth factor, the basis of trust. The basis for my trusting a person may be what I know about the person: a person's competence, knowledge, and skill; or a person's character and general good will; or a person's pledge or promise given to me.

6I can of course connive, maneuver and manipulate, threaten or bribe. But if manipulative or fear-engendering reasons for trusting or accepting trust were to be disclosed to another, this would reduce the prospect of my being helped; Annette Baier makes this point. There are, however, borderline cases where this does not happen. In a relationship characterized by extremes of domination and submission, I could perhaps tell the submissive person why I expect him to help, and he would nonetheless help. I tell him he is my tool, and he agrees merely to be used.

7 There is another feature, to be explored elsewhere, but one that seems essential to analysis of trust: vulnerability. Someone will be hurt, deprived, wounded if the expectation is not fulfilled, if what is entrusted is neglected or damaged. The one who entrusts a good is not indifferent to a felicitous outcome. Annette Baier thinks that vulnerability is an essential feature of non-contractual trust. "Trust," she writes, "is reliance on others' competence and willingness to look after, rather than harm, things one cares about which are entrusted to their care." "Trust and Anti-Trust," 259. Whenever there is trusting, it is possible that harm may come. 
These would be what it is about the person that count as a reason for me to entrust a matter to the person. There may also be non-personal factors that support my entrusting a matter to someone, such as biochemical features of myself or of that other person or of other persons, or the kind of social role I have, as when I delegate a matter to a subordinate. 8 In trusting a thing, similar factors, except for character and good will, give a basis for reliance. With both persons and things, such personal and non-personal factors constitute the fifth element, the "because", involved in reliance trusting. The five elements are, therefore, the subject trusting, the one trusted, the matter or good entrusted or otherwise subject to being affected by the one trusted, the outcome desired and expected, and the basis for the trusting.

Acting on someone's recommendation illustrates these five elements. Someone new to a city trusts a dentist, that she will probably correctly diagnose the source of the pain and provide effective therapy, and the newcomer does so trust because an old friend of his has recommended this dentist and this old friend is shrewd and experienced in health matters, and has himself been skillfully treated by this dentist. The person new to the city is the one who trusts; the dentist is the person trusted; the good entrusted is the health of teeth; the future outcome expected is at least an arresting of pain and stabilizing of a deteriorating situation. The reason for the trusting is the recommendation of the friend. To generalize: in reliance-trust, one person expects and desires and makes it or lets it be possible that another take care of some good, with a delimited range of ends in view; I rely on you to take care of this, to this end, for these reasons. To put the five elements schematically: $X$ trusts $Y$ with $Z$, and has in view the outcome $W$, because of $R$. Thus, reliance-trust is, if I may coin the term, pentadic.

8 Another factor can be even the person's likeness to someone whom I already do trust ("He reminds me of my uncle"), as Laurence Thomas has suggested. See "Trust, Affirmation, and Moral Character: A Critique of Kantian Morality," in his Identity, Character, and Morality: Essays in Moral Psychology (Cambridge, MIT Press, 1991), 254 n. 8. 


\section{I-THOU TRUST}

A second dimension of trust is what I call I-Thou trust.9 It might also be termed intersubjective trust, personal trust, relational trust, intimacy trust.

An approximate conception of 1-Thou trust can be developed by extrapolation from several features of reliance-trusting. Reliancetrusting includes five elements, as we have seen. I-Thou trust, on the other hand, is approximated insofar as expectations become unspecific, insofar as the good entrusted is the very self of the person who does the entrusting, and insofar as the reason for the trusting is the very person of the other trusted. Instead of $X$ trusting $Y$ with $Z$ for $W$ because of $R$, we have $X$ trusts $Y$ with $X$, because of $Y$ : I trust you with myself because of you. I-thou trust is not pentadic but dyadic.

The movement from specific outcomes expected to a lack of specific expectations underscores the way in which reliance-trusting is instrumental and I-thou trusting is not. In reliance-trusting I rely on another to do for me. lexpect the other to act to further my interests, to serve my ends. Of course I may also, or alternately, expect that the one I trust will serve not me but others, will meet not my needs but the needs of those I care about. But whether what I care directly about is my interests or those of someone else, the one trusted is expected not to neglect those interests. The instrumental context is clear when I look for a substitute: if this person cannot take care of my car, I will find someone else who can. In reliance-trusting the other whom I trust is replaceable, fungible at least in principle, even though in my circumstances there may be no substitute actually at hand. 10 In l-thou trust, however, the other is not replaceable.

Intimate trust between friends is one kind of I-thou dyadic trust. There may be relationships wherein I essentially judge it good that this friend be who she is; I am glad that this person lives, but not just for my

9 Martin Buber's I and Thou is a principal inspiration for this proposal; the intersubjective philosophy of Gabriel Marcel is also influential here.

10Replaceability does not imply that the usefulness of the one I trust is just episodic; his or her utility may be continuous, embedded in professional skills or personal character. 
sake. In such a non-instrumental context, to trust a person can be to bring to that person more of myself, where "self" says more than features about me or interests I have. Indeed, my friend may not have certain skills, or may even lack certain character-traits, and in dealing her I do not expect help for certain of my interests; I may and should actually refrain from relying on my friend in some matters.

But I do bring myself--as contrasted with my interests--to this person. I open up to her, and take a chance on what may come of this. While to my doctor I entrust my health, to my friend I entrust my self. I do not withhold my self. I bring to my friend all that I consider close to my very self--mind, heart, body, history, weaknesses, strengths, fears and hopes. In this trust of friendship I do not have a specific outcome in mind. What may result may go beyond each person's (at least conscious) ends. At its highest, this form of trust is troth--an etymological cousin of trust. 11 The plausibility of this kind of trusting is closely linked to the plausibility of a loving that is neither altruistic nor egoistic but appreciative.12

Another way of making clear the contrast between reliancetrusting and I-Thou trusting is to contrast congeniality with intimacy. ${ }^{13}$ If a relationship is one of congeniality, it is the effect on me that I am interested in, 14 perhaps as part of the reciprocally enhancing effects on both of us. We stimulate each other in ways psychological, sexual,

11 Trust, truth, and troth go back to the Old English treowe, trustworthy. The reconstructed Indo-European root is DERU, firm, solid, steadfast; hence, "tree". The American Heritage Dictionary of the English Language, edited by William Morris (New York: American Heritage Publishing Company, and Boston: Houghton Mittlin Company, 1973), 1512.

12| explore these two kinds of trust, and the contrast between relationships of utility and those of appreciation, in my $A$ Philosophy of Human Hope.

13Here I employ a contrast between impersonal congeniality and personal intimacy developed by J. F. M. Hunter in Thinking About Sex and Love (Toronto: Macmillan of Canada, 1980), 85-93. It is like Aristotle's contrast between friendships based on what is useful or agreeable and friendships wherein each values the other for the other's own sake.

14Hunter speaks of these as the output, the performance. 
intellectual, and aesthetic, through conversation, laughter, and silences. Yet I lose interest if such effects wane. The relationship "alters when it alteration finds."

Intimacy is something else. In an intimate 1-Thou relationship, I remain concerned even if the exchanges between us change. Indeed, I pay attention to even her foibles and imperfections, not because I judge them excellent, but because they are hers. I am interested in her, I care for her, and this kind of interest and care is not the same as my interest in her qualities.

Trust based on useful congeniality declines as people become less useful or less agreeable. I-Thou trust is of a different dimension. I am open in my whole person to the whole person of this other, and I am not wary lest some hope or fear of mine come within another's ken. I trust the other, not for contributing to any or to every outcome I am interested in having happen; rather, I trust the other with all that I am. If there is a facet of my life that she is not in touch with, it is not because I withhold it; it just has not come up. The total acceptance of intimacy trust is different from an ability to rely on the totality of every trait of a person for effecting what I want or need.

I am claiming, therefore, that I-thou trusting is neither a form of reliance-trusting nor is it reducible to reliance-trusting, although reliance-trusting usually accompanies I-thou trusting. Nor am I claiming that I-thou trust is common; it may indeed be rare, episodic, at least in its fullest forms. And of course context is needed to enable anyone to distinguish in the concrete between these two dimensions of trust.

While a fuller exposition of the phenomena of trusting would 
include security-trust 15 and openness-trust, I limit myself to these sketches of reliance trust and I-Thou trust, and now turn to relational ontologies.

\section{RELATIONAL ONTOLOGIES}

Ontology, in its root sense, is an account of what is real. 16 Some ontologies propose to be regional--of the human person, for example, or of the subject-matter of the physical sciences. Other ontologies propose to be global, of the entire so-called "furniture of the universe." Some ontological questions are questions of categorizing or typing: is the human mind the same type of reality as the human body? Other ontological questions are about the status of something alleged to be real but not patently so--self or soul, for example, or other minds, or God. Often the method of ontology is to take some type of entity as the benchmark case of what is real, and compare other phenomena to that benchmark in a process of analogical thinking.

15Security trust differs from reliance trust. It is a sense of being basically secure, at-home, upheld in my basic self. It is not a confidence that my particular projects will prosper. It is rather a sense that I belong, am accepted, am OK. I sense ground beneath my feet. Security trust contrasts with Heideggerian Angst. It also contrasts with those strictly limited particular forms of being secure where I am secure from or secure against: "I'm safe as long as I don't go outside." Security-trust is not cosmic, but has a particular here to it.

I find Marcel's description of fundamental existential assurance a helpful formula for security trust. Fundamental existential assurance, he writes, is "the affirmation of an original link, one could even say an umbilical link, which unites the human being, not to the world in general, which would mean nothing, but to a certain determinate ambiance which is as concrete as a cocoon or a nest" (Joan Nowotny's more detailed and literal translation of a passage from Pour une sagesse tragique et son au-delà, 67). The published translation is in Tragic Wisdom and Beyond (Evanston: Northwestern University Press, 1973), 38. metaphysics.

16 Ontology is in some contexts also used as a synonym for 
Some ontologies are explicitly relational. 17 My core meaning of "relational ontology" is one in which the linkage of one with another, especially of self with another, is the benchmark from which what counts as real is measured. The Aristotelian gospel says "In the beginning was substance, ousia." The Cartesian gospel says "In the beginning was self, ego." The gospel of the ontologies I consider now says "In the beginning was the between, das Zwischenmenschliche". More basic than Dasein is Dazwischen. 18

\section{A FEMINIST PERSPECTIVE, THREE TYPES OF RELATION, AND BUBER'S I-THOU.}

I begin my treatment of the relational with feminist philosopher Caroline Whitbeck's argument for a relational ontology. She argues against an ontology that sees self and other as presumed to be different in features and then presumed to be opposed. While her obvious target is the sexual differentiation of male and female as, in the logical sense, complements, for my purposes her most important target is the philosophical convention held by some that self and other are in opposition and cannot fail to have interests that compete. She herself recommends an ontology "based on an understanding of the relation of self and other as a relation between analogous beings. ... Therefore, the distinction between the self and an other does not turn on construing the other as opposite; another distinct being may, and usually does, possess some of the same characteristics as the

17The terms "relational"--and "relation" and "relationship"--have become as helpful or unhelpful as the terms "being" and "Being".

18Were I presenting a more extended study, I would begin with, for example, the explicitly relational metaphysics of Harold Oliver in A Relational Metaphysic (The Hague: Martinus Nijhoff, 1981) and in Relatedness: Essays in Metaphysics and Theology (Macon, GA: Mercer University Press, 1984). Finding Oliver's understanding of relation limited to what John Macmurray calls the mechanical and the organic, I am led to what Macmurray called the specific form of the personal. The relational Thomistic metaphysics of $W$. Norris Clarke is very suggestive at this point, but what he means by personal substance in relation encompasses both the I-It and the 1-Thou relations of Martin Buber; I want to emphasize the distinction between these two manners of interpersonal acting. See W. Norris Clarke, "To Be Is To Be Substance-inRelation," Metaphysics as Foundation: Essays in Honor of Ivor Leclerc (Albany: SUNY, 1993), 164-181. 
self." She resists the framing of ontological issues in ways that would "deny the existence of others, reduce all others to the self--'one soul in two bodies,'--or ... interpret the other as mere material for the self's designs." 19

Whitbeck's thesis supports a point which I have argued elsewhere, that interactional relations can be understood in three ways: as adversarial, as neutral, or as supportive. 20 Thus, the other can be opposed, resistant to my aims; the other can be neutral and "mere material for the self's designs"; or the other can be supportive, an ally with parallel or converging purposes.21

But I further propose that the trifold distinguishing of self-other relations into the adversarial, the neutral, and the allied obtains within what Martin Buber termed the I-It relationship. The I-It relationship is characterized by, to use Buber's terminology, experiencing and using. An other opposes my purposes, or is perhaps malleable to my aims and powers, or has energies and aims allied to mine--all this for the sake of some goal-seeking activity. Relationships of utility, sometimes called subject-object relationships and regardless of whether they obtain in the sphere of knowing or in the sphere of choosing, are types of l-It relationship.

The I-Thou relationship is of a different sort. Where the I-It relationship is selective and goal-directed, the I-Thou relationship is not so restricted. Where in the l-It relation controlling or being controlled is an issue, the I-Thou relationship arises by both grace and will. The I-Thou relationship is a way of relating to human beings, nature, and human "creations," in a word-deed involving the whole

19Whitbeck, Caroline, "A Different Reality: Feminist Ontology," in Beyond Domination: New Perspectives on Women and Philosophy, edited by Carol Gould, New Feminist Perspectives (Totowa, New Jersey: Rowman \& Allanheld, 1984), 81, 82.

20 A Philosophy of Human Hope, 157.

21I wonder whether perhaps there has been some segue from logical opposition and logical complementarity to interpersonal opposition and antagonism, supported by some social commonplaces--the war between the sexes, for example--or by Hegelian philosophy. 
being, a dealing beyond using and experiencing, i.e., beyond goaldirected activities, and "before" separating out (abstracting) qualities or features of the other. It is a word-deed where there is choosing and being chosen, where there is activity approaching passivity. It is a word-deed in which I become a whole being, while a person engages in I-It relationships only partially. Thus even the self of the I-It relationship is different from the self of the I-Thou relationship.

\section{NEGATIVE ONTOLOGY: BUBER}

Martin Buber's understanding of I-Thou relation may indeed point towards an ontology, but a pointer is not a description, let alone an ontology formulated in a conventional way. When one tries to elaborate Buber's I-Thou relationship as an account of what is real, one comes up with negative results: Buber's ontology is a negative ontology. What I mean by this is that the customary and stable language of ontology is the language of $\mathrm{I}-\mathrm{It}$, of disjunctions and classifications and complement classes; mind is--or is not---body, for example. The 1-Thou relationship has a conceptual instability. One reason for this is that I-Thou relationship is more episodic than continuous when compared to l-lt dealings.

Because $\mathrm{I}-\mathrm{It}$ is less episodic, understanding favors the $\mathrm{l}-\mathrm{It}$. As Michael Theunissen put it, quoting Buber: "'You can make yourself understood with others only over it', for it alone--this is how one has to flesh out the rationale--guarantees an identity for the different individual consciousnesses, thanks to that identity that persists through time. ... Now, the impermanent Thou-world is the negation of all this. It is 'unreliable', 'without density', 'without duration', 'incapable of being surveyed', not a possible object of intersubjective understanding."22

The negative result of trying to extrude a conventional ontology out of I-Thou relationships suggests that ontologies may be, to use the scholastic terminology concerning speech about God, not

22Theunissen, Michael, The Other: Studies in the Social Ontology of Husserl, Heidegger, Sartre, and Buber, translated by Christopher Macann (Cambridge, MA: MIT Press, 1984), 328; in the Kaufmann translation of / and Thou, 83-84. 
only of a positive but also of a negative and of a supereminent sort. Buber's I-Thou intimates a via negativa ontology.

\section{MARCEL'S CONTRIBUTIONS}

Marcel's contributions to relational ontologies and the understanding of the phenomena of trusting fall under three headings: intersubjective ontology; the concrete approach to ontology; and the way this is embodied in his analysis of fidelity.

Marcel identifies his ontology as intersubjective, if we can take his answer to the question whether being is intersubjectivity as sufficient warrant.23 Self is tied to other in an underlying unity which is not a totality. The meta-problematical, or the realm of mystery as Marcel calls it, is akin to via negativa and via supereminentiae in ontology. Yet we should not over-inventory the product of such an ontology, mindful that Marcel has told us, "It has become increasingly evident to me that the claim to 'encapsule the universe' in a set of formulas which are more or less rigorously related, is absurd."24

There are vivid similarities between Marcel's concrete approach to ontology and a feminist approach to ontology. Consider this passage from feminist metaphysician Catherine Witt: "The feminine voice is distinguished by two features: the tendency to view interpersonal relations as a basic feature of reality and a high degree of concern for the details of a situation or problem. Feminine reasoning is concrete rather than abstract; it does not operate by smoothing away the details of a problem but tries to accommodate them in their variety and richness. Feminine reasoning assumes

${ }^{23}$ "I concern myself with being only in so far as I have a more or less distinct consciousness of the underlying unity which ties me to other beings of whose reality I already have a preliminary notion." Mystery of Being, I, 223.

${ }^{24}$ Creative Fidelity (New York: Farrar, Straus and Company, 1964), 60, in "An Outline of a Concrete Philosophy." 
relatedness rather than individuality in its descriptions of situations."25 One could substitute "Marcellian" for "feminine": the Marcellian voice is characterized by concern for interpersonal relations and concrete details of a situation. Separated selves conceived according to universal patterns is the style neither of much feminist philosophy nor of Marcel.

In a passage Marcel himself viewed as an epiphany, he wrote that the formula "Being as the place of fidelity" "has for me the inexhaustible inspiration of a musical theme." It suggests "access to ontology."26 I take the access he suggests to be twofold. One is that analysis of fidelity may yield the conviction that to consider fidelity in terms of problem, that is, as an issue or question towards which one can take the view of a dispassionate outside evaluator, is to miss what is central to fidelity, the realm of the meta-problematic. The other is that the meta-problematic realm-I dare to intrude the term "realm" here---includes both the self that is assessing the matter and the veiled presence of a Thou that is not empirical in the usual sense. For Marcel, reflection on fidelity is the path beyond the problematic and beyond the objective, into a territory not mappable by the techniques of conventional ontology.

Marcel's analysis of fidelity is a case par excellence of a concrete approach to ontology, and his analysis suggests a major contribution to reflection on trust. Fidelity is Marcel's word for what I would call intersubjective or I-Thou trustworthiness. To be a person of fidelity is to be a person who is present to another. Words waver in the attempt to say what fidelity is, and the temptation to nail it down in the terminology of I-It is strong. Fidelity is better approached negatively, via remotionis; fidelity is not at its core the reliability of a person who has committed himself or herself to "perseverance in a certain goal," especially out of regard for duty. Marcel calls such

25Witt, Charlotte, "Feminist Metaphysics," in A Mind of One's Own: Feminist Essays on Reason and Objectivity, edited by Louise M. Antony and Charlotte Witt (Boulder, CO: Westview Press, 1993), 281.

26Marcel, Gabriel, Being and Having: An Existentialist Diary (New York: Harper \& Row, 1965, originally 1949), 41. 
resolute readiness to work and to serve "constancy". 27 While the person of fidelity is indeed appropriately constant, he or she is also present. The faithful friend is present for the other, as for thou; the faithful friend is there for me because of me. The friend is not fulfilling some duty, and is not motivated by either a sense of self or a sense of honor or a sense of duty or a desire to be blameless. He or she is not intent upon passing some test. On the contrary, the notion that the behavior of a faithful friend is subject to assessment by some neutral observer is absurd.

Fidelity has a spontaneity that can be neither coerced nor selfdeterminedly willed. As I read Marcel, fidelity arises between myself and another; and continues as a reasonable and good relationship only insofar as it has a necessary link to a Thou not subject to the vicissitudes that would otherwise call fidelity into question.

A person of fidelity creates a self. As Marcel put the matter:

The fact is that when I commit myself, I grant in principle that the commitment will not again be put in question. And it is clear that this active volition not to question something again, intervenes as an essential element in the determination of what in fact will be the case. It at once bars a certain number of possibilities, it bids me invent a certain modus vivendi which I would otherwise be precluded from envisaging. Here there appears in a rudimentary form what I call creative fidelity. My behavior will be completely colored by this act embodying the decision that the commitment will not again be questioned. The possibility which has been barred or denied will thus be demoted to the rank of a temptation. 28

In relegating some possibility to the status of a temptation and in setting myself to contribute to what will be the case, in a certain way 1 create my self. I see Marcel implying here that in the self-creation of fidelity, I trust God that I will not make junk.

27 Yet constancy is not opposed to fidelity; indeed "constancy may be viewed as the rational skeleton of fidelity." Creative Fidelity, 153.

28 Creative Fidelity, 162. 
I suspect that the possibility of self-creation in I-Thou terms would appeal to the concern in feminist philosophy for self-creation in some terms other than those of I-It, of experiencing and using. To make myself present is different from making myself reliable.

The contrast between fidelity and constancy turns not just on the spontaneity of fidelity and the self-centered resoluteness of constancy, but also on the person of fidelity being judged by another to be a faithful friend. The faithful friend is not the person who has his own dutiful reasons for being constant, but is the person, Marcel writes, "who does not fail me, someone who stands up to whatever the circumstances may bring; he [or she] does not slip away, but we find him [or her] there when we are in difficulty." 29 In terms of my dimensions of trust, I judge this friend to be l-Thou trustworthy.

The distinction I make between I-Thou trust and reliance-trust permits us to recognize that this faithful friend will nevertheless decline to accept the entrusting of some goods, even if maximal discretion is afforded. A truly faithful friend can say: You'll have to learn to do that yourself; or: You'll have to get someone else, because taking care of something like that is beyond me.

Thus the good-will-towards-me of reliance-trust is made more sophisticated by Marcel's yoking and contrast of fidelity and constancy. The reliable person can have self-consistency, a sense of duty, a "constancy", as motive; the Marcellian I-Thou trustworthy person has presence to the other, irreducible to reliance.

\section{CONCLUSION}

Since reliance-trust is not the whole story of trusting, it is unhelpful always to imagine trusting as better to the extent that a person entrusts greater goods with ever greater discretion, even to the point of the greatest good with maximal discretion. The truly faithful friend may decline the entrusting of some of the greatest

${ }^{29}$ Creative Fidelity, 154. I find in a line of Simone Weil the spirit of such fidelity: "The love of our neighbor in all its fullness simply means being able to say to him: "What are you going through?'" Quoted in Notre Dame Magazine, May 1980. 
goods, and gently but firmly turn them back. Sometimes the best friend is one who enables another to do for self. Thus the most intelligent way to trust is not solely to ambition better and more accurate reliance. It is also to be open to I-Thou trust, the latter being more a matter of presence to a friend than a matter of instrumental caring for goods a friend lets me take care of. Indeed, sometimes I do well to be suspicious of the well-intentioned assistance offered even by a faithful friend.

The I-Thou ontology suggested by Buber and Marcel is a corrective against considering that human interpersonal relations are accurately understood when they have been analyzed solely in terms of using and being used, even when the using is reciprocal, fair, and knowingly consensual. As some feminist philosophers have argued, one is not better as a person if he or she enters more-carefullyformulated contracts. Nor is better trusting a matter of more discretion, because to leave much to another's discretion is to trust that other still for what that person can do and has chosen to do: that person is simply more widely reliably useful. There is, however, more to genuine human relationships than usefulness. And so there seem to be some phenomena for which the 1-Thou relational model is better suited--better suited for expressing some dimensions of trust and better suited for keeping a person on the lookout for some nonreliance cases of trust. An I-Thou relational ontology, despite or perhaps because of its character as a negative ontology, offers a better fit with a trusting that is not just instrumental reliance.

I return to Marcel's dictum, and ask: How does fidelity give access to ontology? One access I see is that fidelity, as more inclusive than constancy, suggests that an ontology of the person which has categories open only to useful or resolute constancy is an ontology that too thinly describes the powers and realizations of which people are capable and of which they are, indeed, in need. Another access is suggested by Marcel. He suggests that fidelity, at least that of the highest sort, cannot be understood without some appeal to, glimpse of, and backing from, a One who enables fidelity to make sense. As I read Marcel, fidelity crosses into absurdity or at least in some cases into wrongness not only when it is understood as mere constancy but also insofar as the faithful person does not "extend an 
infinite credit to" God. 30 Now this is a line of exploration typically ontological, even if it would proceed via negativa.

I myself think that the phenomena of trust can be a starting point for consideration of some traditional ontological questions, and that the more promising routes for doing so are not Cartesian but relational. But identifying the ontological conditions of possibility for the fidelity of which Marcel speaks is a much larger topic, in Marcel scholarship and in philosophy generally. 31

St. Joseph's University

JOSEPH J. GODFREY, S.J.

${ }^{30}$ Creative Fidelity, 167.

31I am indebted to Julie McDonald for bibliographical help on feminist ontology, and to Elizabeth Linehan for clarifications of some of my ideas. 